\title{
ASPEKT POLSKIEGO CZASOWNIKA JAKO PROBLEM PRZEKLADU ORAZ WYZWANIE DLA UCZĄCYCH SIE I NAUCZAJĄCYCH JĘZYKA POLSKIEGO JAKO OBCEGO
}

\begin{abstract}
Słowa kluczowe: polska gramatyka, nauczanie języka, tłumaczenie, para aspektowa, semantyka, podejście kognitywne

Streszczenie. Artykuł dotyczy zagadnienia słowiańskiego aspektu polskiego czasownika w ujęciu kontrastywnym. Podstawę analizy materiałowej stanowi przekład polsko-niemiecki i niemiecko-polski, a jej systematyczne i kompletne przeprowadzenie umożliwia nowa perspektywa badawcza, którą otwiera kognitywne ujęcie omawianego zagadnienia. Szczególne znaczenie mają tu konkluzje R. Grzegorczykowej i V. Lehmanna dotyczące kognitywnej prymarności lub sekundarności danego partnera w ramach opozycji aspektowej. Płynące z analizy materiału wnioski zogniskowane są wokół następujących problemów: repertuaru wykładników aspektu w języku bezaspektowym, relewancji omawianej kategorii w języku polskim, rzeczywistego udziału kontekstu w wyrażaniu znaczenia opozycji dokonaności : niedokonaności oraz znaczenia wykładnika kognitywnego dla rozpoznawania aspektu. Wyniki przeprowadzonych badań mogą znaleźć zastosowanie nie tylko w praktyce translatorskiej, ale także w glottodydaktyce polonistycznej. Stanowią dobry punkt wyjścia do ponownego otwarcia dyskusji na temat sposobów nauczania aspektu w grupach niesłowiańskich oraz prezentacji omawianego zagadnienia w podręcznikach i innych materiałach dydaktycznych do języka polskiego jako obcego.
\end{abstract}

\section{ZARYS PROBLEMATYKI}

Aspekt polskiego czasownika - mimo liczącej sobie już ponad sto lat naukowej refleksji nad tą kategorią - jest tematem w dalszym ciągu wywołującym kontrowersje wśród językoznawców i tłumaczy, a także nauczycieli języka polskiego jako obcego. Studenci-obcokrajowcy, zwłaszcza ci, którzy pochodzą z krajów spoza kręgu słowiańskiego, opozycję dokonaności : niedokonaności uznają za zagadnienie wyjątkowo trudne, a jego pełne zrozumienie i skuteczne wykorzysty-

*beata_terka@wp.pl, Uniwersytet Jagielloński, Wydział Polonistyki, Katedra Języka Polskiego jako Obcego, ul. Grodzka 64, 31-044 Kraków, ORCID: 0000-0002-0911-2047. 
wanie aspektu w komunikacji postrzegają jako jeden z podstawowych wyznaczników naprawdę dobrego już opanowania zasad rządzących językiem polskim. Lektorzy często także nie są w stanie uspokoić obaw związanych z aspektem, gdyż i dla nich omawiana kategoria nie jest problemem łatwym. Dodatkowym utrudnieniem zarówno dla nauczających, jak i uczących się języka polskiego jako obcego jest sposób prezentowania zagadnienia aspektu w dostępnych na rynku podręcznikach i innych materiałach dydaktycznych - niewolny od rozbieżności i niekonsekwencji. Dlatego też kategorią aspektu nadal zajmować się warto i to najlepiej nie w sposób czysto teoretyczny, a raczej w oparciu o badania materiałowe, które pozwalają uniknąć pułapki tworzenia koncepcji abstrakcyjnych, odbiegających od praktyki językowej.

Badania stanowiące punkt wyjścia niniejszego artykułu miały taki właśnie materiałowy charakter, a ich bazą było thumaczenie polsko-niemieckie i niemiecko-polskie. Poddany analizie materiał obejmował wybrane rozdziały dwóch współczesnych powieści oraz ich tłumaczeń: Tartaku Daniela Odiji oraz Adler und Engel Juli Zeh. Przeprowadzona analiza miała na celu ustalenie zasad ekwiwalencji tłumaczeniowej w zakresie wyrażania znaczeń aspektowych w dwóch systemowo odmiennych językach: w gramatykalizującym kategorię aspektu języku polskim oraz w pozbawionym tej kategorii gramatycznej języku niemieckim, który zdolny jest jednak do wyrażania treści opozycji perfektywności : imperfektywności. Jest to zagadnienie ważne zarówno z perspektywy praktyki translatorskiej, jak i w kontekście nauczania języka polskiego jako obcego - i to nie tylko studentów niemieckich, ale także użytkowników innych języków spoza grupy słowiańskiej.

\section{ASPEKT W UJĘCIU KOGNITYWNYM ${ }^{1}$}

Prezentację wybranych - najważniejszych z perspektywy glottodydaktyki - wniosków płynących z przeprowadzonych badań poprzedzić musi krótkie przypomnienie koncepcji, które, wykorzystując metody semantyki kognitywnej do badań nad aspektem czasownika, otworzyły nową perspektywę badawczą zagadnienia ekwiwalentów thumaczeniowych słowiańskiego aspektu, a tym samym umożliwiły przeprowadzenie analizy materiałowej w sposób systematyczny i kompletny.

Za szczególnie istotne uznać należy konkluzje Renaty Grzegorczykowej (1997) oraz niemieckiego slawisty Volkmara Lehmanna $(1988,1993,2010)$ dotyczące prymarnego bądź sekundarnego charakteru danego partnera aspektowego oraz dokonany przez warszawską językoznawczynię podział czasowników ze względu na ich kognitywną perfektywność lub imperfektywność.

${ }^{1}$ Fragmenty niniejszego podrozdziału pochodzą z niepublikowanej rozprawy doktorskiej mojego autorstwa. 
V. Lehmann twierdzi, że dla danej pary aspektowej niejako bardziej ,naturalne" jest albo znaczenie dokonane, albo niedokonane. Innymi słowy - w ramach opozycji aspektowej jednego partnera uznać można za czasownik alfa - funkcjonalnie typowy, kognitywnie uprzywilejowany i z zasady występujący częściej niż jego odpowiednik o przeciwnym aspekcie, czasownik beta (Lehmann 2010, s. 94). Czasownikami alfa mogą być zarówno perfektywne, jak i imperfektywne leksemy werbalne, w zależności od tego, jaki - jak nazywa to Lehmann - kształt akcjonalny (Lehmann 2010, s. 85): zdarzenie czy przebieg dany czasownik wyraża w sposób podstawowy.

Do podobnych wniosków dochodzi R. Grzegorczykowa (1997). Zdaniem językoznawczyni w prototypowych parach aspektowych, tworzonych przez czasowniki teliczne, partner niedokonany uwydatnia przebieg procesu, a odpowiednik dokonany - zajście zmiany. Te właśnie pary zajmują miejsce najbliżej centrum kategorii aspektu, w ramach której czasowniki podzielić można na dwie podkategorie: prototypowe perfectiva i prototypowe imperfectiva. Należy przy tym pamiętać, że czasowniki nazywające zmiany celowe są prymarnie dokonane, a partnerzy niedokonani w omawianych opozycjach używani są wtedy, gdy profilowaniu podlega sam proces, zdarzenie $\mathrm{w}$ toku, a nie osiągnięcie zmiany albo kiedy istnieje potrzeba zaznaczenia powtarzalności zdarzenia. Czasowniki nazywające zmiany nieteliczne zasadniczo nie wchodzą w opozycje aspektowe, gdyż jako oznaczające zdarzenia nagłe, niezaplanowane, nie posiadają odpowiedników imperfektywnych. Są to zatem z reguły perfectiva tantum, chociaż czasami od niektórych perfectivów nazywających zmiany niecelowe tworzone są też formy niedokonane. W użyciu kursywnym występują one jednak rzadko i potrzebują bardzo specyficznego kontekstu, takiego jak np. praesens historicum, praesens scenicum w uwagach do dramatów czy sytuacji opisu obrazu lub sceny z zatrzymanego filmu. Najczęściej te wtórne imperfectiva są zaś nośnikami znaczenia wielokrotnego.

Podkategoria prototypowych imperfectivów obejmuje natomiast czasowniki statywne, które nie mają w ogóle odpowiedników dokonanych i stanowią tym samym jednolitą grupę imperfectiva tantum. Obok nich sytuują się także kognitywnie imperfektywne czasowniki aktywności nietelicznej, wtórnie perfektywizowane za pomocą przedrostka po-, nadającego oznaczanej aktywności pewną determinację temporalną.

Szczególnie cenne w teoriach V. Lehmanna i R. Grzegorczykowej jest zwrócenie uwagi na kognitywne uprzywilejowanie jednego $\mathrm{z}$ partnerów w ramach opozycji aspektowej oraz występowanie w obrębie kategorii aspektu prymarnych perfectivów i imperfectivów, a w konsekwencji także włączenie klas czasowników jednoaspektowych do jednego kognitywnego spectrum, na co słusznie zwraca uwagę Wacław Cokiewicz (2007, s. 23). 


\section{CELE BADAWCZE}

Spojrzenie na kategorię słowiańskiego aspektu polskiego czasownika jako na problem przekładu polsko-niemieckiego i niemiecko-polskiego zrodziło konieczność przeanalizowania kilku kwestii szczegółowych. Przy kierunku tłumaczenia z języka polskiego na niemiecki najważniejsze było ustalenie repertuaru oraz wzajemnych proporcji środków, za pomocą których opozycja dokonaności : niedokonaności jest wyrażana w języku bezaspektowym. W przypadku tłumaczenia w kierunku przeciwnym natomiast zasadniczym celem było znalezienie odpowiedzi na pytanie o sposób, w jaki tłumacz z języka pozbawionego gramatycznej kategorii aspektu rozpoznaje perfektywność lub imperfektywność czasownika w tekście niemieckiego oryginału. Należało także sprawdzić, czy istnieją konteksty, w których w języku niemieckim czasownik ambiaspektowy wystarcza, jak również ustalić, kiedy i jak często aspekt jest nierelewantny, czyli w języku polskim - jako kategoria obligatoryjna - ma charakter redundantny. Zbadania wymagał również rzeczywisty udział wykładników kontekstowych w wyrażaniu treści opozycji aspektowej w języku niemieckim w celu zweryfikowania powszechnego, choć w dużej mierze intuicyjnego przekonania o dominacji tego rodzaju środków jako indykatorów dokonaności : niedokonaności w językach bezaspektowych. Odwołanie się do ustaleń R. Grzegorczykowej i V. Lehmanna w badaniach materiałowych pozwoliło natomiast ocenić znaczenie wykładnika kognitywnego w identyfikowaniu aspektu oraz określić pozycję tego wykładnika w całym repertuarze ekwiwalentnych eksponentów perfektywności : imperfektywności w języku niemieckim.

\section{WNIOSKI}

Jak pokazały badania, wykładniki aspektowe w tekście niemieckim obejmują: wykładniki kontekstowe, wykładnik kognitywny (związany z kognitywnym sposobem ustalania prymarnej perfektywności lub imperfektywności czasownika), kognitywno-kontekstowe (gdzie kognitywna dokonaność lub niedokonaność czasownika jest dodatkowo wzmocniona przez kontekst) i gramatyczne: formy czasu Präsens w jego podstawowej funkcji oraz formy czasu teraźniejszego użyte do wyrażania przyszłości. Z perspektywy glottodydaktycznej najważniejsze wydaje się omówienie wykładnika kognitywnego, wykładników kontekstowych i sytuacji, w których aspekt jest nierelewantny. 


\subsection{WYKŁADNIK KOGNITYWNY}

W analizowanym materiale wykładnik kognitywny występuje zdecydowanie najczęściej. Przy kierunku tłumaczenia z języka polskiego na niemiecki procentowy udział tego wykładnika w repertuarze funkcjonalnych eksponentów opozycji aspektowej wynosi aż 54 procent. W przypadku thumaczenia w kierunku przeciwnym - 44,7 procent. Poza tymi czasownikami w tekście niemieckim, których polskim odpowiednikiem jest imperfectivum lub perfecivum tantum, kognitywny wykładnik słowiańskiego aspektu wystarcza także czasownikom z polskimi ekwiwalentami w postaci par z wyraźnie dominującym semantycznie jednym z partnerów aspektowych. Dotyczy to przede wszystkim zawsze wtórnie perfektywizowanych czasowników aktywnościowych (przykłady (1)-(2) poniżej), ale także wtórnie niedokonanych czasowników nazywających zmiany niecelowe (przykłady (3)-(4) poniżej) oraz prototypowych par aspektowych, w których prymarny kognitywnie jest partner dokonany (przykład (5) poniżej). W tych dwóch ostatnich przypadkach znaczenie dokonane nie wymaga dodatkowego materialnego wykładnika.

(1) Tak więc szukatem tego Boga (...). $\rightarrow$ Ich suchte also diesen Gott (...).

(2) Stali przed klatka schodowa (...). $\rightarrow$ Sie standen vor dem Treppenhaus (...).

(3) Trzy osoby umarly na zawat. $\rightarrow$ Drei Menschen starben an einem Herzinfarkt.

(4) Zu Hause fand ich sie. $\rightarrow$ Znalazlem ja w domu.

(5) Uszczelnil dach, wymalowal pokoje, wstawil nowe okna. $\rightarrow$ Er dichtete das Dach ab, malte die Zimmer aus, baute neue Fenster ein.

\subsection{ASPEKT NIERELEWANTNY}

Sytuacje, w których aspekt uznać można za nierelewantny, stanowią znaczący odsetek - 12,7 procent $\mathrm{w}$ przypadku tłumaczenia z języka polskiego na niemiecki oraz 4,4 procent przy przeciwnym kierunku thumaczenia. Operacyjnym znakiem tej irrelewancji jest możliwość zastąpienia czasownika dokonanego - niedokonanym (lub odwrotnie) w tekście polskim, bez spowodowania istotnej zmiany znaczenia. Analiza wybranego materiału pozwala przy tym na wyróżnienie pewnych grup kontekstów wpływających na irrelewancję aspektu czasownika użytego w danym zdaniu czy szeregu zdań. Są to:

1. orzeczenia złożone z czasownikiem modalnym (przykłady (1)-(2) poniżej) - przy czym irrelewancję aspektu obserwuje się najczęściej w przypadku wykorzystania czasowników modalnych wyrażających konieczność czy powinność, zdecydowanie rzadziej przy tych wyrażających chęć lub możliwość; 
2. zdania zawierające konstrukcje bezokolicznikowe $\mathrm{z} z u$ (przykłady (3)-(4) poniżej), współwystępujące zresztą niejednokrotnie z czasownikami modalnymi;

3. użycia czasowników mówić : powiedzieć (w tekstach niemieckich konsekwentnie - sagen) w czasie przeszłym dla opisu jednostkowej sytuacji mówienia / powiedzenia czegoś (przykłady (5)-(6) poniżej);

4. zdania lub dłuższe fragmenty tekstu jednoznacznie wskazujące na wielokrotność lub powtarzalność czynności oznaczanej przez dany czasownik (przykłady (7)-(9) poniżej) - tu irrelewancja aspektu wydaje się mieć ścisły związek z kontekstami krotności ograniczonej i powtarzalności uwarunkowanej (terminy te przywołuję za Jadwigą Stawnicką (2007)).

(1) Dwóch musialo ja przytrzymać, bo wyrywała się i wrzeszczała (...). $\rightarrow$ Zwei mußten sie festhalten, weil sie sich losreißen wollte, und sie schrie (...).

(2) Orangensaft, sagt sie. Ich habe welchen da und überlege, ob ich lügen soll. $\rightarrow$ Sok pomarańczowy - mówi. Tym razem jakiś mam, ale zastanawiam się, czy nie powinienem sklamać.

(3) (...) spytat zdecydowanie, na tyle jednak ostrożnie, by nie zaostrzać sytuacji. $\rightarrow$ (...) fragte er entschlossen, aber vorsichtig genug, um die Situation nicht zu verschärfen.

(4) Ich hatte ohnehin nicht vor, jemals wieder die Augen zu öffnen. $\rightarrow(. .$.$) nie zamie-$ rzalem nigdy więcej otwierać oczu.

(5) Ale ojciec mówit, że maty wyzdrowiat i ma się dobrze. $\rightarrow$ Doch der Vater sagte, der Kleine sei gesund und wohlauf.

(6) Was hast du gerade gesagt, Baby? $\rightarrow$ Co powiedziataś przed chwila, Baby?

(7) Nie spodziewat sie po nich zbyt wiele i brat wszystko, co podeszto mu pod krocze. $\rightarrow$ Er setzte keine großen Erwartungen in sie und nahm alles, was ihm unter die Lenden kam.

(8) Gdy odparzyla sobie stopy, zostawiata kalosze w domu i chodzita boso. $\rightarrow$ Wenn sie sich die Sohlen wund rieb, ließ sie die Galoschen zu Haus und ging barfuß

(9) Ein paar Mal rief ich ihren Namen. $\rightarrow$ Kilka razy zawotatem ja po imieniu.

\subsection{WYKŁADNIK KONTEKSTOWY}

Przeprowadzone badania dowodzą relatywnie niewielkiego udziału kontekstu, dość powszechnie uznawanego za najczęściej występujący substytut aspektu, jako wykładnika omawianej słowiańskiej kategorii gramatycznej. Jego udział w tekście niemieckiego tłumaczenia wynosi 20 procent, a w tekście niemieckiego oryginału $-8,1$ procent. Wykładnik kontekstowy stanowi samodzielny indykator aspektu wyłącznie w sytuacjach, w których w tekście użyty zostaje niedokonany partner czasownika prymarnie perfektywnego. W takich przypadkach imperfektywność sygnalizuje odpowiedni okolicznik wskazujący na duratywność lub iteratywność danej czynności (przykłady (1)-(2) poniżej), spójnik zdania 
okolicznikowego czasu während (przykład (3) poniżej), spójnik złożony zdania porównawczego je... desto (przykład (4) poniżej) albo - najczęściej - szerszy kontekst językowy, który wprowadza znaczenie powtarzalności (przykład (5) poniżej).

(1) Ale któregoś dnia patrza ze szczytu muru, który budowali, a tam na dole stoi (...) Szczerbatka. $\rightarrow$ Doch eines Tages schauten sie von einer Mauer hinunter, die sie gerade errichteten, und dort unten stand die Zahnlückige (...).

(2) (...) die immer ohne Absender kamen (...). $\rightarrow$ (...) które zawsze przychodzily (...) bez podania nadawcy (...).

(3) Diese Melodie glaubte ich zu hören, während ich die Ziffern eintippte (...). $\rightarrow Z d a$ wało mi się, że słyszę ja, wstukując poszczególne cyfry (...).

(4) A im dlużej opowiadal, tym więcej musial stawiać. $\rightarrow$ Und je länger er erzählte, desto mehr mußte er spendieren.

(5) Wieczorem, gdy już trochę ich zmogło, przychodzili do Myśliwskiego na kolację. Siadali przed telewizorem. $\rightarrow$ Am Abend, wenn sie schon erschöpft waren, gingen sie zu Myśliwski zum Essen. Sie setzten sich vor den Fernseher.

\section{IMPLIKACJE DLA GLOTTODYDAKTYKI POLONISTYCZNEJ}

Płynące z przeprowadzonych badań wnioski mogą znaleźć zastosowanie nie tylko w praktyce translatorskiej, ale także w glottodydaktyce polonistycznej. Prowadzić powinny one przede wszystkim do ponownego otwarcia dyskusji nad sposobem nauczania aspektu zwłaszcza w grupach niesłowiańskich.

Warto raz jeszcze zastanowić się może nie tyle nad kolejnością wprowadzania poszczególnych członów opozycji aspektowej, bo tę dyktuje niejako zdolność czasowników niedokonanych do wyrażania teraźniejszości, ale nad możliwością wcześniejszego niż w dotychczasowej praktyce dydaktycznej wprowadzania zagadnienia aspektu - równolegle z czasem przeszłym, tak by od razu ćwiczyć użycie partnerów aspektowych kognitywnie prymarnych oraz nie doprowadzać do sytuacji produkowania przez uczących się zdań wątpliwych, nienaturalnych lub zwyczajnie niepoprawnych (w czasie przeszłym i przyszłym), np. *Wczoraj kupowatem jedzenie $i$ wracatem do domu., *Jutro będę iść do kina.

Warto rozważyć też możliwość omówienia ze studentami grupy czasowników statywnych, by uświadomić uczącym się specyfikę tych leksemów werbalnych, zapobiegając tym samym pokusie tworzenia fałszywych opozycji aspektowych (typu lubić : polubić, znać : poznać) oraz klasy czasowników aktywnościowych z partnerami determinatywnymi, aby umożliwić dostrzeżenie różnicy między dubletami tego typu a prototypowanymi parami aspektowymi.

Uświadomienie sobie kognitywnego uprzywilejowania jednego z partnerów aspektowych może natomiast ułatwić zarówno lektorom, jak i autorom podręczników prezentowanie zasad dotyczących użycia czasowników dokonanych i nie- 
dokonanych - między innymi uwolnić od konieczności czy choćby tylko potrzeby „wymyślania” i powielania nieprawdziwych reguł związanych ze stosowaniem zwłaszcza form perfektywnych (np. wyrażanie przez czasownik dokonany czynności, która miała miejsce tylko jeden raz / o konkretnej godzinie / wczoraj lub łączenie dokonaności czasownika z jego występowaniem w ramach struktury najpierw..., a potem...).

Zdanie sobie sprawy z istnienia kontekstów, w których kategoria może być nierelewantna ustrzec może natomiast (zwłaszcza uczących grupy obcokrajowców na niższych poziomach zaawansowania językowego) przed tworzeniem przykładów niefortunnych, dopuszczających więcej niż jedną prawidłową formę.

Konieczne wydaje się też zwrócenie większej uwagi na iteratywne znaczenie czasowników niedokonanych, o którym studenci czasami zapominają. Przykłady wprowadzające kontekst powtarzalności czy wielokrotności są wprawdzie dość licznie reprezentowane w materiałach dydaktycznych, ale być może warto konstruować ćwiczenia pokazujące w ramach jednego tekstu różne znaczenia tych samych czasowników niedokonanych.

Wnioski z przeprowadzonych badań materiałowych mogą wreszcie stanowić dobry punkt wyjścia do krytycznej analizy sposobu prezentacji zagadnienia aspektu w dostępnych na rynku podręcznikach i innych materiałach dydaktycznych wykorzystywanych w nauczaniu języka polskiego jako obcego. Przydatna byłaby zwłaszcza ich kompleksowa analiza pod kątem podawanych zasad dotyczących użycia czasowników dokonanych i niedokonanych, kolejności wprowadzania poszczególnych partnerów aspektowych na różnych poziomach zaawansowania językowego, stopnia intuicyjności (sugerującej rozwiązania najbardziej prototypowe) w prezentowaniu kategorii aspektu, jak również najczęściej powtarzających się w rozdziałach poświęconych aspektowi błędów oraz możliwych przyczyn ich występowania.

\section{BIBLIOGRAFIA}

Cockiewicz W., 2007, Na peryferiach aspektu, „LingVaria”, 2 (4), s. 9-25.

Grzegorczykowa R., 1997, Nowe spojrzenie na kategorię aspektu w perspektywie semantyki kognitywnej, w: R. Grzegorczykowa, Z. Zaron (red.), Semantyczna struktura stownictwa $i$ wypowie$d z i$, Warszawa, s. 25-38.

Lehmann V., 1988, Der russische Aspekt und die lexikalische Bedeutung des Verbs, „Zeitschrift für slavische Philologie", nr 48, s. 170-181.

Lehmann V., 1993, Die russischen Aspekte als Gestufte Kategorien (Ein Beispiel für die Bedeutung der kognitiven Linguistik in der slavistischen Sprachwissenschaft), „Die Welt der Slaven”, $38 / 2$, s. 265-297.

Lehmann V., 2010, Der slavische Aspekt im Licht der kognitiven Linguistik, w: T. Anstatt, B. Norman (red.), Die slavischen Sprachen im Licht der kognitiven Linguistik, Wiesbaden, s. 77-99.

Odija D., 2003, Tartak, Wołowiec. 
Odija D, 2006, Das Sägewerk, thum. M. Pollack, Wien.

Stawnicka J., 2007, Aspekt - iteratywność - określniki kwantyfikacyjne: na materiale form czasu przeszłego w języku polskim, Katowice.

Zeh J., 2003, Adler und Engel, München.

Zeh J., 2004, Orty i anioły, tłum. S. Lisiecka, Warszawa.

Beata Terka

\section{ASPECT OF POLISH VERBS AS A PROBLEM OF TRANSLATION AND A CHALLENGE FOR LEARNERS AND TEACHERS OF POLISH AS A FOREIGN LANGUAGE}

Keywords: Polish grammar, language teaching, translation, aspectual pair, semantics, cognitive approach

Summary. The article concerns the issue of Slavonic aspect of Polish verb in the contrastive approach. The base for the contrastive analysis is Polish-German and German-Polish translation. Empirical research could finally be conducted in a complete and systematic way thanks to the new research perspective opened by applying cognitive semantics methods to the relevant issue. Here, the theories of Renata Grzegorczykowa and Volkmar Lehmann (concerning the primary or secondary cognitive character of each aspectual partner) are of particular importance. Conclusions drawn from the analysis focus on the following issues: the repertoire of functional exponents of aspect in German, the relevance of the category in Polish, the true importance of contextual and cognitive indicators of perfectiveness or imperfectiveness of verbs. The results are relevant from the perspective of translators and translation, but they can also be applied to the field of glottodidactics. They can provide a solid base for reopening the discussion on the ways of teaching aspect to students from non-Slavic countries and presenting the relevant issue in course books and other teaching materials. 